\title{
Chronic retinal vein occlusion in glaucoma
}

\author{
R. A. HITCHINGS AND G. L. SPAETH \\ From Moorfields Eye Hospital, London, and Wills Eye Hospital
}

An association between acute central retinaljvein occlusion and chronic simple glaucoma has been recognized for many years (Moore, 1922; Braendstrupp, 1950; Becker and Post, 195I; Bertelson, 1961; Raitta, 1965). The incidence of glaucoma in acute central retinal vein occlusion is reported to range from 9 to 43 per cent (Braendstrupp, 1950; Bertelson, 196r). In most instances, the patients were not known to have glaucoma before development of the occlusion (Sugar, 1942; Braendstrupp, 1950; Vannas and Tarkkanen, 1960); in cases in whom glaucoma was present, it was not far advanced (Bertelson, 196r; Wise, Dollery, and Henkind, 1971a).

The relationship of retinal vein occlusion with cases of long-standing chronic simple glaucoma is less well understood. Bertelson (196r) did not find a single case of central retinal vein occlusion on reviewing 296 eyes with 'mainly chronic' glaucoma (Bertelson, 1961). Dobree (1957), in a survey of 200 glaucomatous eyes, found eight eyes with abnormal venous channels on the optic disc that might have indicated an earlier central retinal vein occlusion. Wise and others (197rb) felt that the 'usual type of vein obstruction due to glaucoma is occlusion of the central retinal vein late in any kind of chronic glaucoma. The obstruction develops insidiously in cases with moderate to marked cupping of the disc'. Kohner and Shilling (1976) when discussing branch retinal vein occlusions felt that a hemisphere vein occlusion, where the occlusion occurred 'on the optic disc at the edge of the optic cup' was a type of vein occlusion unquestionably associated with chronic glaucoma.

The diversity of opinion prompted this investigation into the relationship of retinal vein occlusion with chronic glaucoma.

It is the purpose of this paper to describe the clinical features of central and hemisphere retinal vein occlusion in glaucoma. The incidence of these types of retinal vein occlusion in patients attending a glaucoma clinic will be given. Finally, the effect that those retinal vein occlusions may have on the prognosis for the glaucoma will be discussed.

Address for reprints: R. A. Hitchings, FRCS, Department of Clinical Ophthalmology, Moorfields Eye Hospital, City Road, London ECrV 2PD

\section{Material and methods}

Patients attending the Glaucoma Service at Wills Eye Hospital between October 1973 and April 1975 were examined for evidence of earlier central or hemisphere retinal vein occlusion. Occlusion of the central retinal vein was considered to have occurred if retino-ciliary collateral channels on the optic disc or vein loops on the disc surface, suggesting collaterals within the disc, were discovered (Wise and others, 197 Ic). A hemisphere vein occlusion was considered to have occurred if veno-venous anastomoses nasal and temporal to the optic disc along a horizontal meridian were present.

Patients diagnosed as having suffered an earlier retinal vein occlusion were subjected to a full ophthalmic examination. This included applanation tonometry, gonioscopy, fundoscopy, and an examination of the visual field with a Goldmann perimeter using two, and usually three, different sized test objects. In addition, Goldmann and Hruby lens examination of the posterior pole, ophthalmodynamometry corrected for intraocular pressure, stereoscopic disc photography, and fluorescein angiography were carried out whenever possible. (In several patients these examinations were precluded by permanently miosed pupils, and/or lens opacities.) Particular note was made of the presence or absence of spontaneous pulsation of the retinal veins on the optic disc, and the existence of retinal haemorrhages and exudates.

\section{Results}

Eighteen patients-10 White and eight Black-(26 eyes) had evidence of earlier central or hemisphere retinal vein occlusion. This number comprised 2 per cent of patients attending the Glaucoma Service during the study period. These patients could be divided into two groups:

\section{Group I: End stage glaucoma :}

a. With venous loops and/or collateral vessels identifiable on the optic disc: eight patients, 14 eyes

b. With retinal veno-venous anastomoses: four patients, four eyes

Group II : Early-moderate glaucoma : With venous loops and/or collateral vessels identifiable on the optic disc: six patients, eight eyes 


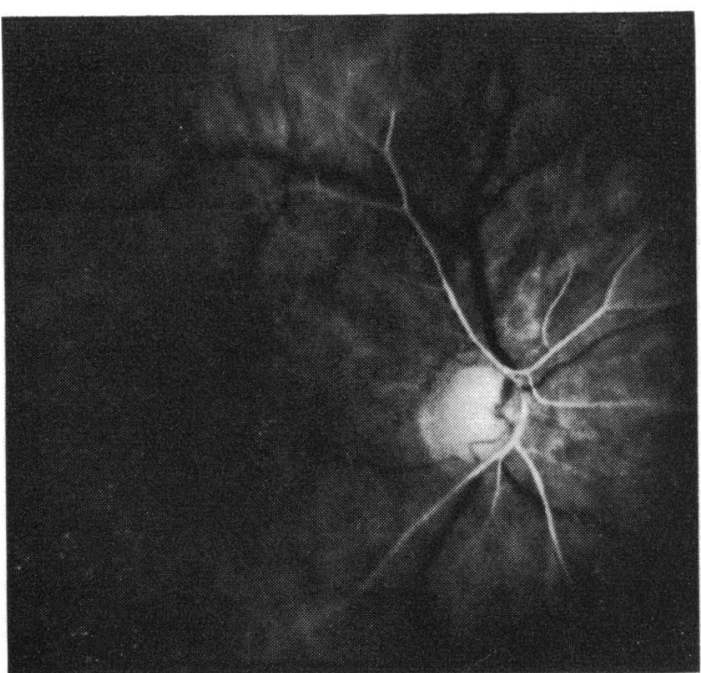

( $\mathrm{a} a)$

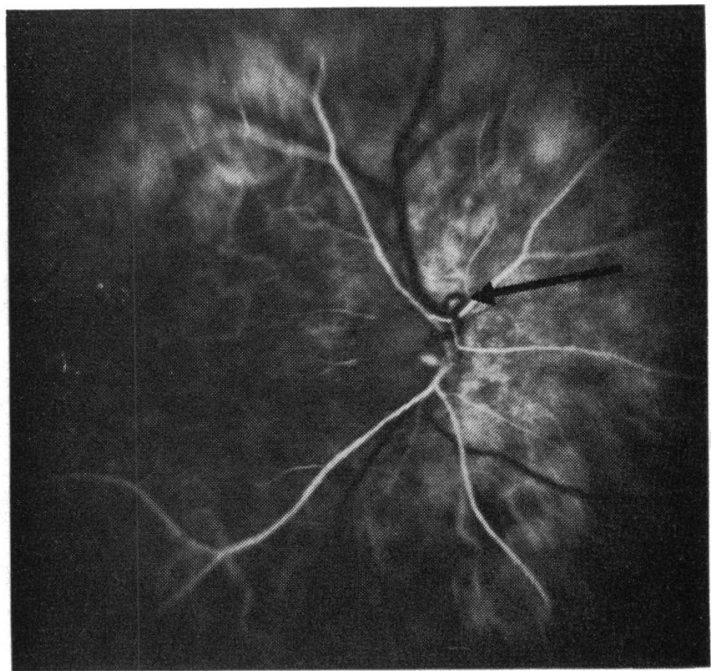

( $\mathrm{r} b)$

FIG. I a and b (Patient 6) Demonstrates development of a venous loop (arrowed) within a 22-month period

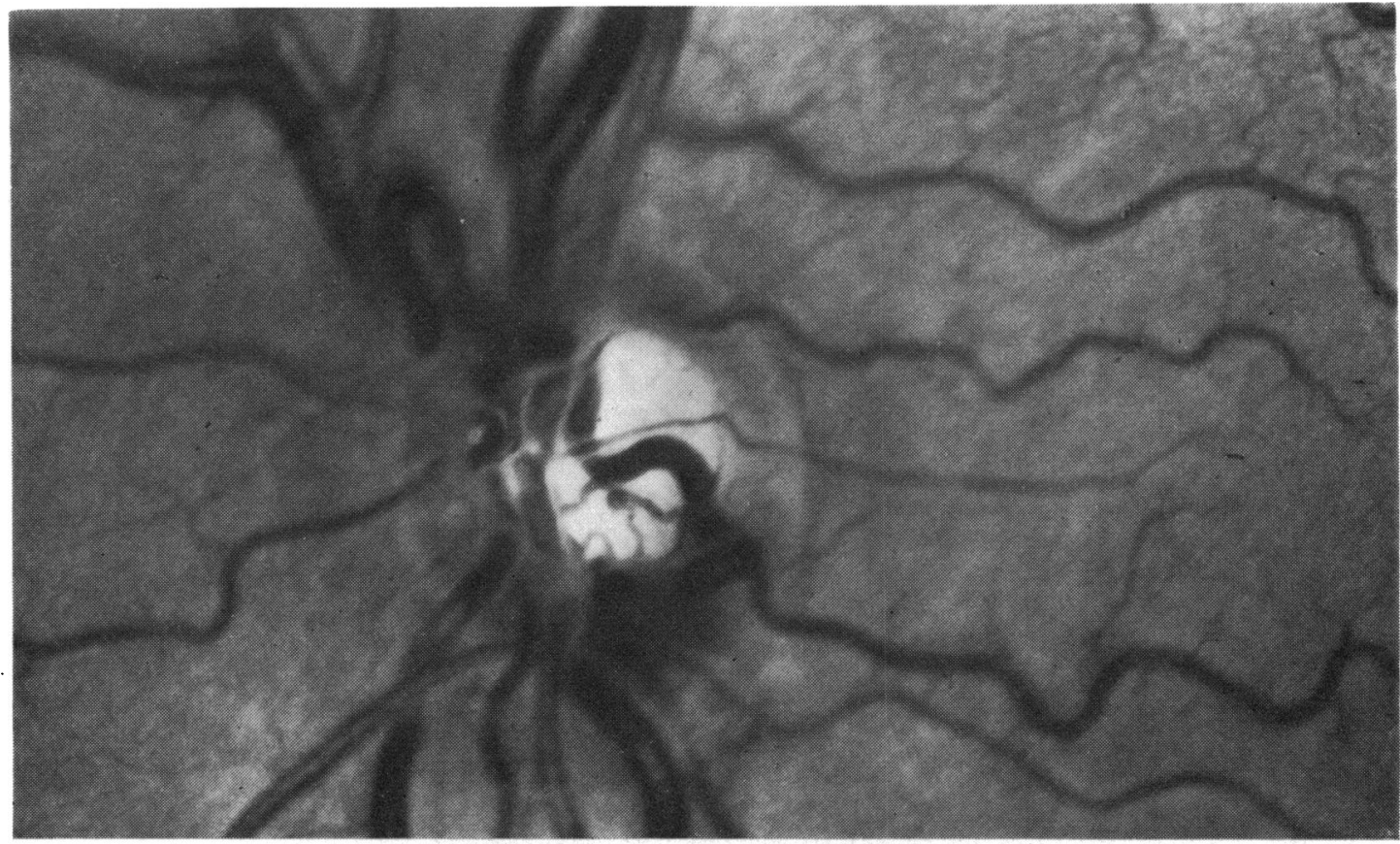

FIG. 2 (Patient 16) Multiple venous loops in patient with glaucomatous cupping and no loss of visual fieli

End stage glaucoma refers to eyes with a central field of $10^{\circ}$ or less, or a residual temporal island. Early to moderate glaucoma refers to eyes with raised intraocular pressures and definitely cupped optic discs with visual field loss ranging from minimal or no field-loss to a loss of approximately one-half of the visual field.
The clinical features of these patients are shown in the Table. The development of venous loops within a 22-month period is shown in Figs $r a, b$, Patient 6. Marked venous loops in a patient with cupping and no field loss are shown in Fig. 2, Patient 16. Multiple veno-venous anastomoses are shown in Fig. 3, Patient ro. 
Table Clinical data of patients with chronic retinal vein occlusion

\begin{tabular}{|c|c|c|c|c|c|c|c|c|c|c|}
\hline $\begin{array}{l}\text { Patient } \\
\text { no. }\end{array}$ & $\begin{array}{l}\text { Group } \\
\text { no. }\end{array}$ & $\begin{array}{l}\text { Date of } \\
\text { examination }\end{array}$ & $\begin{array}{l}\text { Age } \\
\text { (years) }\end{array}$ & Sex & Race & \multirow[b]{2}{*}{ Right } & \multirow{2}{*}{$\frac{l \text { acuity }}{\text { Left }}$} & Visual field & \multirow[b]{2}{*}{ Left } & $\begin{array}{l}\text { Intraoc } \\
\text { pressure }\end{array}$ \\
\hline \multirow{3}{*}{$\mathbf{I}$} & \multirow{3}{*}{ Ia } & & & \multirow{3}{*}{ Female } & \multirow{3}{*}{ Black } & & & Right & & Right \\
\hline & & 30.03 .73 & 40 & & & $6 / 9$ & NPL & $5^{\circ}$ Central island & Nil & 44 \\
\hline & & 13.08 .74 & 41 & & & $6 / 9$ & NPL & Unchanged & Unchanged & 20 \\
\hline 2 & Ia & 29.08 .74 & 73 & Male & White & CF & CF & Temporal island & Temporal island & 60 \\
\hline 3 & la & 15.01 .74 & 68 & Female & White & $6 / 60$ & $\mathbf{H M}$ & $5^{\circ}$ Central field & $5^{\circ}$ Central field & 58 \\
\hline 4 & la & 20.11 .73 & 40 & Male & Black & $6 / 60$ & HM & $5^{\circ}$ Central island & $3^{\circ}$ Central island & 38 \\
\hline & & 23.01 .75 & 41 & & & $6 / 60$ & HM & Unchanged & Unchanged & 14 \\
\hline $\mathbf{5}$ & Ia & 26.08 .70 & 72 & Male & Black & $6 / 12$ & HM & $5^{\circ}$ Central island & 3 Central island & 30 \\
\hline & & 01.07 .74 & 76 & & & $6 / 60$ & NPL & $3^{\circ}$ Central island & $\begin{array}{l}\text { Nil } \\
\text { Full }\end{array}$ & 22 \\
\hline 6 & Ia & 26.03 .71 & 53 & Female & White & $6 / 15$ & $6 / 9$ & Lower arcuate & $\begin{array}{l}\text { Full } \\
\text { Full }\end{array}$ & $\begin{array}{l}30 \\
50\end{array}$ \\
\hline & & $\begin{array}{l}18.03 .73 \\
28.01 .74\end{array}$ & $\begin{array}{l}55 \\
56\end{array}$ & & & $\begin{array}{l}\mathbf{H M} \\
\mathbf{H M}\end{array}$ & $\begin{array}{l}6 / 6 \\
6 / 6\end{array}$ & $\begin{array}{l}\text { Temporal island } \\
\text { Temporal island }\end{array}$ & Full & $\begin{array}{l}50 \\
18\end{array}$ \\
\hline 7 & Ia & 25.09 .74 & 60 & Female & Black & $\mathbf{H M}$ & $6 / 5$ & Temporal island & Full & 50 \\
\hline 8 & Ib & 09.09 .74 & 77 & Female & White & $6 / 9$ & $6 / 9$ & $\begin{array}{l}\text { Superior altitudinal } \\
\text { hemianopia }\end{array}$ & $\begin{array}{l}\text { Superior altitudinal } \\
\text { hemianopia }\end{array}$ & 32 \\
\hline 9 & $\mathbf{l b}$ & 19.02 .72 & 43 & Male & Black & NPL & $6 / 9$ & Nil & Lower arcuate & 35 \\
\hline & & 20.02 .75 & 46 & & & NPL & $6 / 24$ & Unchanged & Unchanged & 17 \\
\hline 10 & Ib & 27.01 .75 & 46 & Male & Black & NPL & $6 / 15$ & Nil & $5^{\circ}$ Central island & 48 \\
\hline 11 & Ib & 15.01 .75 & 47 & Female & Black & $6 / 60$ & NPL & $5^{\circ}$ Central island & Nil & 13 \\
\hline $12 t$ & lc & 04.06 .75 & 55 & Female & White & $6 / 12$ & $6 / 60$ & $5^{\circ}$ Central island & $5^{\circ}$ Central island & 50 \\
\hline 13 & II & 03.02 .71 & 37 & Female & White & $6 / 12$ & $6 / 15$ & Apparently full & Apparently full & 57 \\
\hline & & 17.04 .74 & 50 & & & $6 / 12$ & $6 / 15$ & Unchanged & Unchanged & 14 \\
\hline & & 17.02 .75 & 51 & & & $6 / 12$ & $6 / 15$ & Unchanged & Unchanged & 12 \\
\hline 14 & $1 I$ & 08.01 .73 & 45 & Female & Black & $6 / 9$ & $6 / 60$ & Lower sector defect & Lower sector defect & 33 \\
\hline & & 23.03 .74 & 46 & & & $6 / 9$ & $6 / 60$ & Unchanged & Unchanged & 18 \\
\hline 15 & II & 11.03 .74 & 24 & Male & White & $6 / 12$ & $6 / 15$ & Lower sector defect & Lower sector defect & 57 \\
\hline & & 12.06 .74 & 25 & & & $6 / 12$ & $6 / 15$ & Unchanged & Unchanged & 15 \\
\hline 16 & II & 02.03 .75 & $\mathbf{2 2}$ & Male & White & $6 / 9+$ & $6 / 9+$ & Full & Full & $2 \mathbf{I}$ \\
\hline 17 & II & 30.09 .74 & 50 & Male & White & $6 / 9$ & $6 / 9$ & Full & Full & 20 \\
\hline 18 & II & 08.02 .71 & 33 & Female & White & NPL & $6 / 12$ & Nil & Lower sector defect & 38 \\
\hline & & 29.06 .73 & 35 & & & NPL & $6 / 9$ & Nil & Unchanged & 34 \\
\hline & & 24.01 .75 & 37 & & & NPL & $6 / 9$ & Nil & Unchanged & 24 \\
\hline
\end{tabular}

*ODM = Ophthalmodynamometry

$\ddagger$ Maculopathy right and left. Venous statis reinopathy right and left

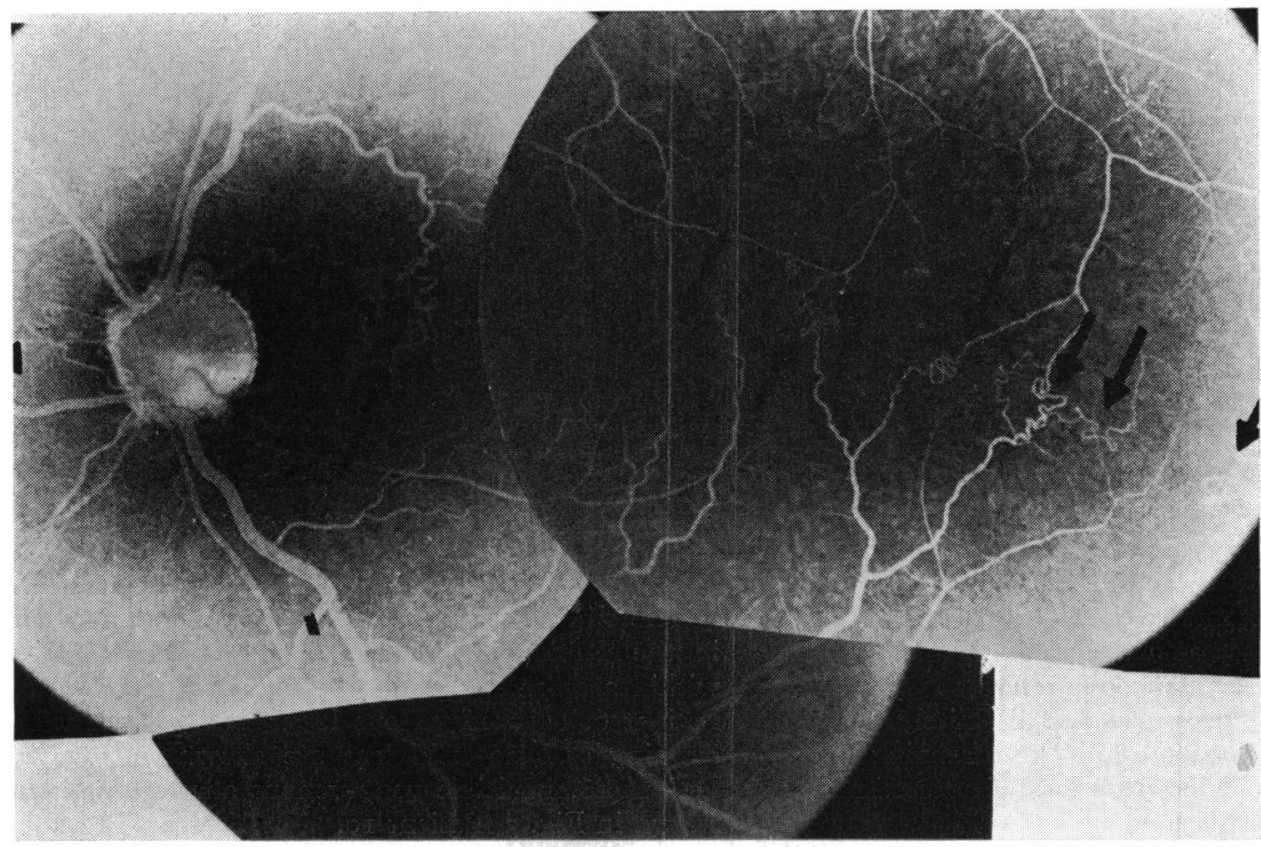

FIG. 3 (Patient 10) Multiple veno-venous anastomoses (arrowed) in patient with hemisphere vein occlusion 


\begin{tabular}{|c|c|c|c|c|c|c|c|c|c|c|}
\hline \multicolumn{2}{|c|}{$\begin{array}{l}\text { rtical cup/disc } \\
\text { tio }\end{array}$} & \multicolumn{2}{|c|}{$O D M^{*}$} & \multicolumn{2}{|c|}{$\begin{array}{l}\text { Spontaneous venous } \\
\text { pulsation }(S V P) \dagger\end{array}$} & \multirow[t]{2}{*}{$\begin{array}{l}\text { Systemic } \\
\text { blood pressure }\end{array}$} & \multicolumn{2}{|c|}{$\begin{array}{l}\text { Venous loops }(L) \text { or } \\
\text { collaterals }(C) \text { on optic disc }\end{array}$} & \multicolumn{2}{|c|}{$\begin{array}{l}\text { Retinal vein anastomoses } \\
\text { temporal to macula }\end{array}$} \\
\hline ght & Left & Right & Left & Right & Left & & Right & Left & Right & Left \\
\hline ) & I.O & - & - & - & 一 & - & No & L & - & 一 \\
\hline ) & I. 0 & - & - & Absent & Absent & - & No & L & 一 & - \\
\hline ) & 0.9 & - & - & Absent & Absent & - & $\mathrm{L}, \mathrm{C}$ & $\mathrm{L}, \mathrm{C}$ & No & No \\
\hline ) & 0.8 & - & - & Absent & Absent & $140 / 90$ & $\mathrm{~L}$ & $\mathbf{L}$ & No & No \\
\hline ) & 0.9 & - & - & 一 & - & - & - & - & - & - \\
\hline ) & 0.9 & $75 / 43$ & $64 / 42$ & Absent & Absent & $116 / 82$ & $\mathrm{~L}, \mathrm{C}$ & $L, C$ & No & No \\
\hline 7 & I. & - & - & & - & - & $\mathrm{L}$ & L, C & No & No \\
\hline 3 & $1 \cdot 0$ & - & - & Absent & Absent & $140 / 86$ & $\mathrm{~L}$ & L, C & No & No \\
\hline 3 & 0.2 & - & - & - & - & - & - & - & - & - \\
\hline$)$ & 0.2 & - & - & - & - & - & $\mathrm{L}$ & No & 一 & - \\
\hline ) & 0.2 & - & - & Absent & Present & - & $\mathrm{L}$ & No & No & No \\
\hline ) & 0.4 & - & - & Absent & Present & 一 & L, C & No & No & No \\
\hline 3 & 0.9 & - & - & Absent & Present & - & $\mathbf{L}$ & $\mathbf{L}$ & No & Yes \\
\hline ) & 0.9 & - & - & & & - & No & No & Yes & - \\
\hline ; & 0.9 & $67 / 35$ & $64 / 38$ & Absent & Absent & $140 / 94$ & No & No & Yes & No \\
\hline ) & 0.9 & - & - & Present & Absent & $122 / 80$ & No & No & No & Yes \\
\hline ; & 0.9 & - & - & Present & Absent & - & No & No & No & Yes \\
\hline ; & 0.9 & $60 / 17$ & $70 / 45$ & Absent & Absent & 一 & L, C & $\mathrm{L}, \mathrm{C}$ & No & No \\
\hline$j$ & 0.8 & - & - & - & - & - & 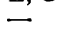 & - & - & - \\
\hline j & 0.8 & 一 & - & - & 一 & - & L & $\mathbf{L}$ & 一 & - \\
\hline j & 0.8 & $55 / 13$ & $60 / 17$ & Absent & Absent & $120 / 65$ & $\mathbf{L}$ & $\mathbf{L}$ & No & No \\
\hline ) & 0.9 & - & - & - & - & $\begin{array}{r}136 / 68 \\
\end{array}$ & No & L & - & - \\
\hline ) & 0.9 & $57 / 35$ & $57 / 35$ & Absent & Absent & $128 / 76$ & No & L & No & No \\
\hline 3 & 0.8 & - & - & - & - & $\begin{array}{l}118 / 74 \\
\text {. }\end{array}$ & L & L & - & - \\
\hline 3 & 0.8 & $60 / 47$ & $60 / 49$ & Absent & Absent & $132 / 80$ & $\mathrm{~L}$ & L & No & No \\
\hline ; & 0.7 & $62 / 32$ & $64 / 35$ & Present & Absent & $124 / 80$ & No & L & No & No \\
\hline ; & 0.4 & $40 / 22$ & $50 / 22$ & Present & Absent & $122 / 80$ & No & $\mathrm{L}, \mathrm{C}$ & No & No \\
\hline ) & 0.3 & - & - & - & - & - & No & $\mathrm{L}$ & - & - \\
\hline j & 0.8 & - & 一 & 一 & - & $106 / 62$ & No & L & No & - \\
\hline$?$ & 0.8 & - & $37 / 22$ & - & Absent & $106 / 54$ & No & $\mathbf{L}$ & - & No \\
\hline
\end{tabular}

VP referred to as absent only when elicited at, or just below ,diastolic arterial pressure; and present only when visible at the current intraocular ressure or with gentle digital pressure

Fourteen patients (22 eyes) had evidence of an earlier central retinal vein occlusion, six eyes had readily recognizable retino-ciliary collateral veins at the optic disc, the remainder had venous loops suggesting retino-ciliary collateral vessels within the optic nerve. None of these patients had a history of sudden loss of visual acuity and none had arterial attenuation or sheathing. One patient (two eyes) had (peripheral) retinal haemorrhages; these occurred in the only patient with a maculopathy. No patient had cotton-wool spots. Six of these patients underwent fluorescein angiography, in no case could fluorescein staining of vessel walls, fluorescein leakage, capillary closure, or macular changes be seen. Each of these patients had non-pulsatile retinal veins at the optic disc, ophthalmodynamometry suggesting that in every case venous pressure was at or just below diastolic 'ophthalmic artery' pressure.

Four patients had retinal veno-venous anastomoses indicating an earlier hemisphere retinal vein occlusion. No patient had a history of sudden loss of visual acuity. No patient had retinal haemorrhages. Each patient had non-pulsatile veins on the optic disc. Ophthalmodynamometry suggested a marked increase in retinal vein pressure to just below diastolic artery pressure in each case.

\section{Discussion}

INCIDENCE

Acute central retinal vein occlusion severe enough to produce visual symptoms is not infrequently associated with undiagnosed and/or 'not far advanced' glaucoma (Sugar, 1942; Braendstrupp, 1950; Vannas and Tarkkanen, 1960; Bertelson, 1961; Wise and others, 1971a). Asymptomatic central retinal vein occlusion is much more likely to be overlooked. The 2 per cent incidence of central and hemisphere retinal vein occlusion found in our series (cf. eight in 200 eyes found by Dobree (1957)), is probably spuriously low. The fact that no patient in this series was followed-up by the clinic from a known acute (haemorrhagic) central vein occlusion, is of interest. It might reflect a uniformly bad prognosis for all such patients in the clinic, progression to thrombotic glaucoma precluding their occlusion. It might 
also reflect their transfer to the Retinal Service of the hospital and subsequent loss to follow-up.

\section{PRECIPITATING FACTORS}

Many factors both systemic and local may decide whether, and at what stage of the glaucomatous disease, an eye with chronic simple glaucoma develops occlusion of the central retinal vein. Suggested factors include distortion at the laminar cribrosa (Behrman, 1962; Klein and Olwen, 1956; Emery, Landis, Paton, Boniuk, and Craig, 1974) and dystrophic changes in the wall of the central retinal vein (Verhoff, I913 ; Salzman, 1939). Each of these factors may have contributed in our cases. Arterial disease has been considered an important factor (Hayreh, 1965, I97I; Paton, Rubenstein, and Smith, 1965). However, in our patients, ophthalmodynamometry did not reveal low 'ophthalmic artery' pressures, nor did fundoscopy reveal gross arterial disease.

Similar factors may be invoked in the pathogenesis of hemisphere vein occlusions; of special importance is the distortion of the affected vein along its course within an enlarged optic cup (Kohner and Shilling, 1976). It was not possible to identify the site of the obstruction in any of the four eyes with this type of retinal vein occlusion. Because of the difficulties in examining these particular patients, it was not possible to distinguish between upper and lower half retinal vein pressures at the optic disc (although this has been done with other patients). Similarly, in the one patient who underwent fluorescein angiography, it was not possible to determine which way, from upper to lower half of the retina or vice-versa, the venous blood flowed to circumvent the block.

\section{CLINICAL FEATURES}

Wise and others (197Ib) ascribed the mild clinical picture of central retinal vein occlusion to a lack of functioning retina and reduced inflow of arterial blood. The identical clinical picture in eight eyes designated early-moderate glaucoma requires an alternative hypothesis. Kohner and Shilling (1976) when describing the clinical variations after acute thrombosis of the central retinal vein noted that mild cases undergo 'resolution'. According to these authors, 'mild' central retinal vein occlusions have few, if any, initial visual symptoms, the cottonwool spots and haemorrhages disappear and retinociliary collateral channels develop at the optic disc. All except two eyes described in this paper fit into this category, 20 eyes showing resolution of central retinal vein occlusion, four eyes resolution of hemisphere vein occlusion. Only one patient (two eyes) was seen with retinal haemorrhages.
Six eyes had readily recognizable retino-ciliary veins at the optic disc, four had veno-venous anastomoses draining blood away from the side of the obstructed 'hemisphere' vein, and the remainder had venous loops at the optic disc considered to indicate retino-ciliary collateral vessels. However, each patient had a marked increase in retinal vein pressure at the optic disc, to levels just below diastolic ophthalmic artery pressure. The development of bypass channels had not allowed return of a normal pressure differential between retinal artery and vein, and the obstruction to central and hemisphere retinal vein outflow must have persisted.

An alternative explanation for the mild clinical symptoms seen in our patients is retinal vein occlusion of gradual onset. If enlargement of the optic cup in chronic glaucoma with resultant distortion of its contained retinal veins is a major factor in pathogenesis, the occlusion would be slow and progressive with a gradual increase in retinal vein pressure. The concomitant elevation of intraocular pressure associated with glaucomatous cupping would ensure that there would be no marked increase in transmural hydrostatic pressure across small vessels from elevated vein pressure that might result in intraretinal haemorrhages. Long-standing increase in retinal vein pressure at the optic disc would allow time for the retinociliary collaterals of central vein occlusion and veno-venous collaterals of hemisphere vein occlusion to occur.

Although central or hemisphere retinal vein occlusion of gradual onset associated with chronic elevation of intraocular pressure would explain the clinical features in our patients, it is not possible to rule out a mild acute occlusive episode of any of them.

Eight patients were seen after their intraocular pressure had been brought under control, with a follow-up of one to four years. No patient was noted to have developed retinal haemorrhages after control of his intraocular pressure, as might be expected from the resultant increase in transmural hydrostatic pressure across small retinal vessels. This may reflect the comparatively slow reduction of intraocular pressure achieved by 'medical' means, it may also reflect changes in the retinal vascular system secondary to prolonged increase in retinal vein pressure. No patient showed signs of a further venous occlusive episode, and none had evidence for a marked worsening of his glaucoma (but five of the eight patients had end stage glaucoma when first seen). Every patient had persistence of the venous loops, retino-ciliary collaterals, and veno-venous anastomoses where previously noted. No patient had developed spontaneous pulsations of the central retinal vein, each showing persistence of elevated retinal vein pressure, although ophthal- 
modynamometry proved too inaccurate to say whether the retinal vein pressures had decreased. These unchanging features suggest persistence of the retinal vein obstruction throughout this followup period. To what extent the obstruction is reversible is unknown, but if related to distortion of the optic cup, it may be permanent. Unless the resistance of the new retinal vein outflow system diminishes abnormal vascular haemodynamics will persist. Elevation of retinal vein pressure reduces effective perfusion pressure of the inner retina and, probably, the optic disc (but cf. McLeod and Ring, 1976). Long-term reduction in perfusion, by affecting nutrition could affect function, and render the retina and optic disc more susceptible to the effects of any subsequent increase in intraocular pressure.

\section{Summary}

Asymptomatic chronic retinal vein occlusion that occurs in chronic simple glaucoma is described. The condition is characterized by marked elevation of retinal vein pressure with collateral vessels and vein loops at the optic disc in cases of central vein occlusion, or retinal veno-venous anastomoses along a horizontal line temporal and nasal to the disc in hemisphere vein occlusion. No patient had visible arterial changes, capillary closure, fluorescein leakage, or haemorrhages. The vein occlusion was not limited to 'end stage' glaucoma.

The role of increased intraocular pressure and glaucomatous enlargement of the optic cup with retinal vein distortion in the pathogenesis of the condition was stressed.

Follow-up of these patients revealed persistence of the retinal vein occlusion shown by elevated retinal vein pressures. This would reduce effective perfusion of the inner retina and optic disc and may affect the long-term visual prognosis.

We thank Mr R. K. Blach and Mr D. McLeod for helpful criticism.

This investigation was supported by National Institutes of Health Research Grant EY0067704 from the National Eye Institute.

\section{References}

BECKER, B., and POST, L. T. (1951) Amer. F. Ophthal., 34, 677

BEHRMAN, S. (1962) Brit. $\mathcal{F}$. Ophthal., 46, 336

BERTELSON, T. I. (1961) Acta ophthal. (Kbh.), 39, 603

BRAENDSTRUPP, P. (1950) Ibid., 28 (Suppl), 35

DOBREE, J. H. (1957) Trans. ophthal. Soc. U.K., 77, 229

emery, J. M., Landis, D., Paton, D., Boniuk, M., and Craig, J. M. (1974) Trans. Amer. Acad. Ophthal.

Otolaryng., 78, 290

HAYREH, S. S. (1965) Brit. Y. Ophthal., 49, 626

(1971) Amer. F. Ophthal., 72, 998

KLEIN, B., and OLWEN, J. H. (1956) Arch. Ophthal., 56, 207

KOHNER, E., and SHILlING, J. (1976) Retinal vein occlusion in 'Medical Ophthalmology,' ed. Clifford Rose,

chap. 28. Chapman \& Hall, London

MCLEOD, D. L., and RING, C. P. (1976) Brit. F. Ophthal., 60, 419

MOORE, R. F. L. (1922) Trans. ophthal. Soc. U.K., 42, 115

PATON, A., RUBENSTEIN, K., and SMITH, v. H. L. (1965) Ibid., 84, 559

RAITTA, c. (1965) Acta ophthal. (Kbh.), 43 (Suppl), 83

Salzman, H. (1939) Arch. Ophthal., 140, 629

SUGAR, H. S. (I942) Ibid., 28, 587

VANNAS, S., and TARKKANEN, A. (1960) Brit. $\%$. Ophthal., 44, 583

VERHOFF, F. H. L. (1913) Arch. Ophthal., 42, 145

WISE, G. N., DOLLRRY, C. T., and HENKIND, P. (1971a) Diseases of capillary and venous insufficiency in 'The Retinal

Circulation', chap. 14, p. 375. Harper \& Row, New York

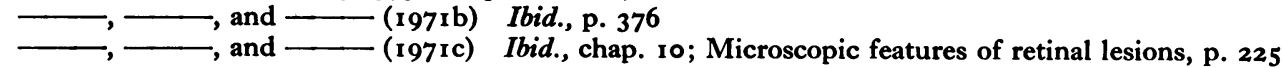

